\section{THE 'RITE OF SPRING'}

Stravinsky's ballet score details a pagan ritual in which a sacrificial virgin dances herself to death. This is a far step away from the clinical trial performed by Carmen Houben and colleagues (see page 328 ) which investigated nurse-led advanced care planning in patients with advanced COPD and their loved ones. This multicentre cluster randomised-controlled trial delivered a structured $90 \mathrm{~min}$ advanced care planning session to patients and their loved ones. 165 patients were randomised with quality of patient-physician end-of-life care communication higher in the intervention group. In addition, anxiety symptoms were lower in loved ones and similar in the patients in the intervention and control group at 6 month follow-up. Depression in both patients and loved ones were similar. So, a nurse-led ACP-intervention session improves end-oflife care communication without causing psychosocial distress in both patients and loved ones. Now that is something to dance about.

\section{PREDICT A RIOT}

The Rite of Spring at its premiere, at the Théâtre de Champs-Elysées, provoked such a response of bad behaviour by the audience that a riot ensued in the theatre. Although behaviour modification was the aim of the Chest Australia Trial, the trial was designed to promote positive health behaviours in individuals at increased risk of lung cancer. Jon Emery and colleagues (see page 362) delivered the intervention of a consultation to implement a self-help manual followed by self-monitoring reminders to promote help-seeking for respiratory symptoms. 551 participants were randomised with a $40 \%$ relative increase in respiratory consultations in the intervention group with no difference in time to first respiratory consultation, total consultation rates or measures of psychological harm. If the results of this behavioural intervention can be shown to enhance respiratory health, it will lead to riotous applause.

\section{CAN'T SEE THE WOOD FOR THE TREES?}

After a long winter, Spring is on us and the leaves are appearing on the trees. In this month's Thorax we have two editorials (see pages 321 and 323) which help us to see the wood for the trees in causal inference studies. They comment on a recent methodology paper from across the pond (Ann
Am Thorac Soc 2019;16(1):22-28) which gives guidance on conducting observational studies which aim to make a causal inference. The paper (and the Thorax editorials) introduce us to directed acyclic graphs which help make explicit confounding, mediation and collider bias. The paper will guide you through the tangled undergrowth of "back door pathways" and help you find a way through the woods.

\section{A LUNG HEALTH CHECK IN THE "BIG SMOKE"}

You might go to your local shopping centre for a loaf of bread and a pint of milk, but would you go there for a low dose chest CT? In the journal this month (see page 405), Crosbie and colleagues, from Manchester, report the results of an evaluation which invited older smokers and ex-smokers to "lung health checks" next to local shopping centres. Most of those who agreed to CT were from a deprived background and were at high risk of lung cancer. Of those screened, 3\% had lung cancer and $65 \%$ of those went on to have surgical resection. The authors conclude that this approach to screening engages with those in deprived areas and plan wider "roll out" of the service. Coming soon to a shopping centre near you?

\section{SPRING HAS SPRUNG}

As in springtime, Fraser Brims and colleagues (see page 354) considered a fresh new approach to the management of malignant pleural mesothelioma. They performed a randomised controlled trial to investigate the effect of early specialist palliative care on quality of life. This multi-centred randomised controlled trial compared early referral to specialist palliative care (within 3 weeks) vs standard care in the UK and Western Australia. 174 participants were randomised with no difference in health related quality of life observed between the intervention and standard care group at 3 months. Indeed, there was no difference at 3 month and 6 months between the groups in any of the secondary endpoints. The authors concluded that there is no role for routine referral to specialist palliative care soon after diagnosis of mesothelioma in centres with access to palliative care services already. It is not a case of 'out with the old and in with the new', but let's keep the old, in particular, if it is good.

\section{SUMMER IN THE LIGHT AND WINTER IN THE SHADE}

Charles Dickens characters were not exposed to much Vitamin D and it has been postulated that Tiny Tim may well have had Rickets. Spring heralds that time when 'the sun shines hot and the wind blows cold' but will this be enough to prevent exacerbations of COPD. In this issue of Thorax (see page 337) Dr Jolliffe and colleagues describe a Systematic Review and Meta-analysis of Vitamin D supplementation for the treatment of acute exacerbations of COPD. They found no effect in those where the sun had worked it's magic although there was a benefit in those whose baseline vitamin D levels were below $25 \mathrm{nmol} / \mathrm{L}$. To paraphrase Mark Twain, what COPD patients need is a bit of 'spring fever'.

\section{LIKE THE SPIRIT OF LOVE FELT EVERYWHERE}

Percy Bysshe Shelley wrote 'And each flower and herb on Earth's dark breast, rose from the dreams of its wintry rest' to describe spring. Unfortunately the imagery of herbs rising from a dark breast also conjures visions of acid reflux which when rising from its wintry rest can promote the development of idiopathic pulmonary fibrosis. In this issue of Thorax (see page 346) Dutta and colleagues describe their feasibility study to suppress acid reflux in patients with IPF. They had to screen 280 patients to recruit 45 into this double blind study. While they demonstrated feasibility there was a small increase in infection and reduction in FVC in those treated with omeprazole. Maybe we should wait for hell to freeze over before embarking on a definitive trial.

FROM LEAFY TREES TO BRONCHIAL TREES... This weeks teaser image shows an abnormality of the bronchial tree. See page 420 for more.

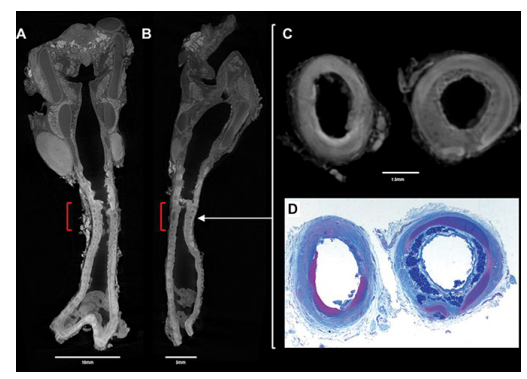

(C) Author(s) (or their employer(s)) 2019. No commercial re-use. See rights and permissions. Published by BMJ. 